\title{
Designing a Project Management Integrated System
}

\author{
Houda TAHRI \\ IMOSYS - EMI, Morocco \\ htahri@gmail.com
}

\begin{abstract}
The assurance of a good project tracking from the analysis of his opportunity until its realization is the basic condition for its success. This tracking requires making available, the project manager or PMO, of a variety of tools that support the managerial activity and optimize the time available to management. The purpose of this study is to define a project management system that integrates twelve management functionalities (planning, project portfolio management, Content Management, collaboration platform, issues management, deliverables management, resource management, Change management, Configuration management, Workflow Management, Electronic document management and Satisfaction surveys). Thus, final system will integrate, in addition to the key features found in existing project management software, five additional functionalities and a specific additional module of portfolio management to support multi-criteria analysis projects and maturity assessment of project management.
\end{abstract}

Keywords: Project management system, project portfolio management, collaboration software, IT tools, maturity assessment

\section{Introduction}

The assurance of a good project tracking from the analysis of his opportunity until its realization is the basic condition for its success. This tracking requires making available, the project manager or PMO, of a variety of tools that support the managerial activity and optimize the time available to management. I quote mainly templates, historical documents, management procedures as well as IT tools for planning and collaboration: simple (Excel, MS Project ...) or advanced (software, specific development ...). This article focuses on the planning and collaboration software. Indeed, they allow the integration of templates and documents, the involvement of stakeholders in real time and procedures automation. It thus comprises:

- Benchmarking based on an examination of a sample of project management software;

- Proposal to incorporate new features into the project management system;

- Design of a specific module for project portfolio management.

\section{Literature Review}

A web search uncovered a wide variety of project management products from proprietary tools to free tools and substantially covering the following main features:

Planning: In business dictionary, planning is a basic management function involving formulation of one or more detailed plans to achieve optimum balance of needs or demands with the available resources. In project management domain, planning consist on elaborating progressively high-level Information into detailed plans throughout the project life cycle (PMI, 2013), it is involves identifying and schedule project tasks, estimating their duration and cost and determining the resources needed to achieve them in order to monitor and report on project progress and optimize its realization expenses. While in portfolio management domain, planning means creating and maintaining necessary processes and communication relative to the aggregate portfolio (PMI, 2013).

Deliverables Management (DM): monitors the progress of deliverables throughout the project lifecycle to project completion, not only through traditional indicators costs and time, but also in terms of quality deliverables and meeting customers' expectations outstanding project. 
Issues management (IM): This function allows users to capture incidents or problems encountered; some of them are configurable and allow managing all tickets types (support request or assistance) or even make proposals for improvement. This function allows:

- Improving the quality of deliverables;

- User satisfaction and customers;

- Traceability and accountability of stakeholders;

- Team productivity;

- Expenditure reduction (Blair, 2004).

Collaboration Platform (CP): is a platform, usually web-based, enabling collaboration between several people. Collaboration is the process of creating collectively shared representations and emerging processes and results that reflect the contribution of all participants (Elliot, 2007). This platform allows:

- centralizing and sharing projects documents,

- notification and reporting new contributions or comments of others regarding deliverables issued,

- Improving productivity.

Project Portfolio Management (PPM): The Project portfolio management software allows a user to obtain, manage and report on client data (Ricardo, 2005). This software allows:

- Managing dependencies between projects,

- Decision making to engage projects,

- Reporting on the projects progress,

- Sharing resources,

- Financial analysis,

- Risk Analysis.

Resource management (RM): is a functionality that allows you to manage the resources allocated to projects in order to:

- Optimize the use and the distribution of competences,

- Manage workload of project resources,

- Minimize risks related to the availability of resources and anticipate the needs of recruitment or contracting.

Electronic Document Management (EDM): is a function that:

- Organize project documents,

- Scan paper documents and store them,

- Manage all documentation (indexing, classification and distribution of documents).

Benchmarking on project management software: A web search uncovered a wide variety of project management products from proprietary tools to free tools and substantially covering the main features. We present below, in a comparative grid containing functionalities described above, a No-exhaustive and varied list of fifty products, the most used and highly ranked by Gartner in the last five years. In the following table are mentioned the top ten of Cloud-Based IT Project and Portfolio Management Services (Gartner, 2015a) and IT Project and Portfolio Management Software Applications (Gartner, 2015b).

\section{Analyses and Results}

Results analyses: On the sample shown below, we have:

- $10 \%$ of the presented products are free software,

- $92 \%$ of the products presented, of which five are free, covering $86 \%$ of the main features described above.

- $64 \%$ of these products, of which two are free, covering all of said features.

- $86 \%$ of these products are available in all types of areas. 
However, these products do not cover all functionalities that project manager and PMO need to fulfill their missions. Hence the opportunity to focus on additional features.

Description of the target system: The target system is a project management integrated system that provides global visibility into the organization, standardization, measurement and process improvement, and that will help with effective decision making by providing key performance indicators, analysis and reporting functions and project portfolio optimization tools.

It will integrate well:

- Twelve Families of management features, five of them are new, each described in a module for stakeholders.

- The administration and security module such role and access management.

New functionalities include:

Content Management: Content management is a very interesting feature that should be part of project management tools; its purpose is the management of electronic content and the knowledge base of the company, namely:

- The creation or establishment of electronic document,

- Storage and indexing,

- Cleaning,

- Distribution and publishing,

- Research and archiving

The knowledge base comprises historical projects, framework documents (project management plan, project charter, RACI matrix, risk register, register of stakeholders), internal or external policies (safety policy, procurement regulation), procedures, lessons learned. This knowledge base is shared securely by all stakeholders on the Web it either inside or outside the company.

Table1 : List of 50 Project management solutions

\begin{tabular}{|c|c|c|c|c|c|c|c|c|c|c|c|}
\hline Logiciel & $\mathbf{C P}$ & 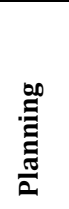 & PPM & $\mathbf{R M}$ & EDM & IM & DM & 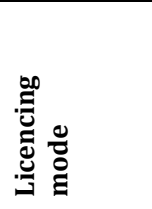 & 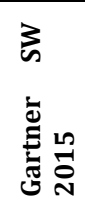 & 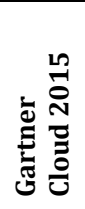 & 范 \\
\hline AtikTeam & Yes & Yes & Yes & Yes & Yes & Yes & Yes & Proprietary & & & $\begin{array}{l}\text { Tout } \\
\text { domaine }\end{array}$ \\
\hline AtTask/workfront & Yes & Yes & Yes & Yes & Yes & Yes & Yes & Proprietary & & 2 & $\begin{array}{l}\text { Tout } \\
\text { domaine }\end{array}$ \\
\hline Automation center & Yes & Yes & Yes & Yes & Yes & Yes & Yes & Proprietary & $>10$ & & $\begin{array}{l}\text { Tout } \\
\text { domaine }\end{array}$ \\
\hline BrightWork/sharepoint & Yes & Yes & Yes & Yes & Yes & Yes & Yes & Proprietary & & & $\begin{array}{l}\text { Tout } \\
\text { domaine }\end{array}$ \\
\hline CA Technologies & Yes & Yes & Yes & Yes & Yes & Yes & Yes & Proprietary & 2 & & IT \\
\hline ChangePoint/Daptiv & Yes & Yes & Yes & Yes & Yes & Yes & Yes & Proprietary & 4 & 4 & IT \\
\hline Clarizen & Yes & Yes & Yes & Yes & Yes & Yes & Yes & Proprietary & & 3 & $\begin{array}{l}\text { Tout } \\
\text { domaine }\end{array}$ \\
\hline CoPTrack & Yes & Yes & Yes & Yes & Yes & Yes & Yes & Proprietary & & & $\begin{array}{l}\text { Tout } \\
\text { domaine }\end{array}$ \\
\hline Easy Projects .NET & Yes & Yes & Yes & Yes & Yes & Yes & Yes & Proprietary & & & $\begin{array}{l}\text { Tout } \\
\text { domaine }\end{array}$ \\
\hline Efficient360 & Yes & Yes & Yes & Yes & Yes & Yes & Yes & Proprietary & & & $\begin{array}{l}\text { Tout } \\
\text { domaine }\end{array}$ \\
\hline $\begin{array}{l}\text { Endeavour Software } \\
\text { Project Management }\end{array}$ & Yes & Yes & Yes & Yes & Yes & Yes & Yes & Free & & & IT \\
\hline EPM360 & Yes & Yes & Yes & Yes & Yes & No & Yes & Proprietary & & & IT \\
\hline Genius & Yes & Yes & Yes & Yes & Yes & Yes & Yes & Proprietary & 9 & & Tout \\
\hline
\end{tabular}




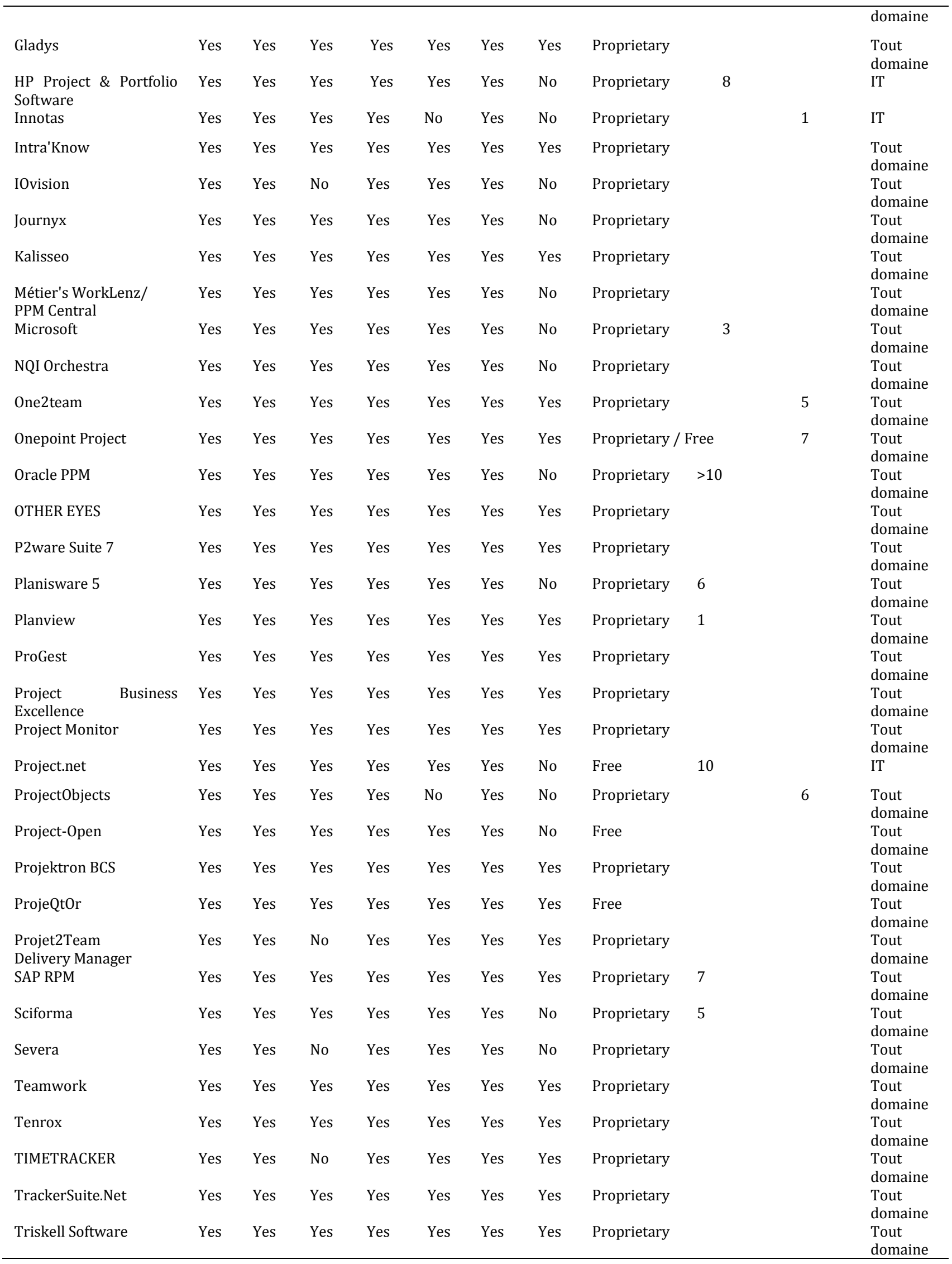




\begin{tabular}{lcccccccccc}
\hline Upland Software & Yes & Yes & Yes & Yes & Yes & Yes & Yes & Proprietary \\
VPMi/VCSonline & Yes & Yes & Yes & Yes & Yes & Yes & Yes & Proprietary \\
WorkEngine/SharePoint & Yes & Yes & Yes & Yes & Yes & Yes & Yes & Proprietary \\
Tout & &
\end{tabular}

Change management: Change management is a function that allows:

- Tracing change requests,

- Following their statutes,

- And automating their processing.

Configuration management: This feature aims to trace the versions of documents and other information on the projects. It records different states of a project and keep track of the modification date. This functionality is a part, generally, of content management software.

Workflow Management: Some processes and project procedures are easier to manage if they we use a workflow management tool; this tool allows defining the tasks to be undertaken by each actor and automate the validation circuit (exp. resource allocation, acquisition of materials, project team training, change request, vendor payments, quality control and authorization a work execution).

Management of satisfaction surveys: The customer satisfaction surveys are highly recommended at the end of the project for future improvements and for the evaluation of completed projects. For this, we propose in this platform software, a customizable online survey model to suit the needs of the business.

\section{Conclusion \& Recommendations}

This work is a basic design and development of an integrated project management and project portfolio system. It gives developers an idea about the different features to integrate into the target system and to provide API for interfacing with existing solutions. The developer can use one of free software presented in this study and complete it by the missing features. This study will help both the customer and the developer to define the development project scope of the integrated project management system, which is a necessary condition for the success of any project.

\section{References}

Blair, S. (2004). A Guide to Evaluating a Bug Tracking System". Retrieved from Scribd.com: http://www.scribd.com/doc/7046090/A-Guide-to-Evaluating-a-BugTracking-System

Elliot, M. A. (2007). Stigmergic collaboration - A theoretical framework for mass collaboration. Melbourne, Centre for Ideas - Victorian College of the Arts, The University of Melbourne, $240 \mathrm{p}$.

Gartner. (2015a). Magic Quadrant for Cloud-Based IT Project and Portfolio Management Services, Worldwide.

Gartner. (2015b). Magic Quadrant for IT Project and Portfolio Management Software Applications, Worldwide.

PMI. (2013). A Guide to the Project Management Body of Knowledge (PMBOK Guide). Fifth Edition, p 8-10.

Ricardo, C. (2005). The impact of project portfolio management on information technology projects. International Journal of Project Management, 23(7), 524-537. 